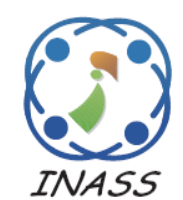

\title{
Student Learning Context Analysis by Emotional Intelligence with Data Mining Tools
}

\author{
Samuel Peter James $\mathbf{I}^{1^{*}} \quad$ Ramasubramanian $\mathbf{P}^{2} \quad$ Magdalene Delighta Angeline $\mathrm{D}^{3}$ \\ ${ }^{I}$ Department of Computer Science, \\ Bharathiyar University, Coimbatore, Tamilnadu, India \\ ${ }^{2}$ Department of Computer Science and Engineering, \\ Shadan Women's College of Engineering and Technology, Hyderabad, India \\ ${ }^{3}$ Department of Computer Science and Engineering, \\ Dr. G.U. Pope College of Engineering, Thoothukudi, Tamilnadu, India \\ * Corresponding author's Email: i.samuelpeterjames@gmail.com
}

\begin{abstract}
The emotions of human in every part of a life are usual and unavoidable. The emotions uplift or cast down a person facing different situations in each moment. The main objective of this research work is to provide learning with emotional-based approach and to analyze the result using data mining algorithms. This paper examine how emotions involve the learners learning and the success of performance improvement of various learners under different environment that leads to the success of a learner. This study scrutinize the Emotional Intelligence (EI) and how it relates to academic performance. The key idea is to bring out different learning environments that focus on the learners' positive emotional behavior and proceed according to the observed behavior. The proposed work uses Observe, Amend and Analysis (OAA) Method in the learning environment to enhance the learners learning and to evaluate performance using Data Mining Tools to enhance the future outcome. The experimental results show that with the proposed approach the learners learning is improved with positive emotions.
\end{abstract}

Keywords: Multi-layer perception, Emotion, Emotional-based learning, Positive emotion, Emotional intelligence, Data mining tools, Educational data mining, Ensemble algorithm, Decision tree.

\section{Introduction}

The learner's learning pattern and motivation are identified with the study of emotions in classrooms. [1]. Emotional practice plays a key role in learning and is an important component of all school activities [2]. Positive and supportive classroom climates are associated with the goal-directed behavior, but negative and non-supportive and vague climates are associated with evasion, distraction and dishonest behavior.

Similarly, it has been found that students in high-involvement classrooms (defined by happiness, motivation to learn and a student discourse reflecting identified with the class) report significantly more experiences of flow [3] than do students belonging to low-involvement classrooms
[4]. As we can infer from the arguments above, in learning contexts such as classrooms, students may be especially sensitive to the emotional meanings of their academic experiences, as well as to the experiences of their classmates, who are in such close proximity and are socially relevant [5]. Although research has shown that teachers have the strongest and most direct impact on students with psychological experience in the classroom [6] peer emotional relationships also have an important effect on children's attitude towards both school and themselves. However, to date, we do not have a reliable and valid measure of a collective construct to examine such emotional interaction from the perspective of Emotional Intelligence.

The relationship between emotions and learning is more complex. The mediating role of feelings 
modification and expressions modification has been examined by some recent studies [7]. Although there are relatively consistent data indicating that heightened negative emotions, such as anxiety, typically hinder learning, and do so by generating an extraneous cognitive load, the effect of positive emotions is less predictable. [8 - 10] Previous studies have shown that positive emotions can improve learning by increasing motivation and enhancing problem solving, but others have demonstrated the opposite effect whereby positive emotions are inversely associated with learning. [11, 12] The conditions under which positive emotions facilitate or suppress learning are unclear, but it has been suggested that all emotions generate an extraneous cognitive load and thus the net effect of positive emotions may depend upon their interactions with other sources of cognitive load. Also, [13] in their own research on the imparting of emotional intelligence elements on Academic Achievement discovered a significant relationship between self-awareness, emotional management and empathy with academic achievement at the level of $p<0.05$. [14] in their study of the influence of emotional intelligence on academic achievement among students of faculty of education, Universiti Teknologi Mara (UiTM), reported that emotional intelligence was found to be significantly and positively associated with the academic achievement of the preserves teachers that participated in the study. The relationship between EI and health is evaluated in [15] where the capacity that EI has demonstrated to prevent somatic and psychological issues on other professional groups completely different work settings such as teachers or nurses, among others.

Moreover, [16] stated that emotional intelligence has proven to be a better predictor of future success than traditional methods like Grade Point Average (GPA), Intelligence Quotient (IQ) and standardized test scores. Emotions help to self-motivate and work towards goal achievement. The actions and thoughts of a learner are influenced by their emotions. The proposed work induces learner's positive emotional thoughts and learning is made enhancing the thinking ability to bring out new ideas in the learning environment. This Emotional-based learning help the learner to obtain more knowledge in the specific subject. The learner enjoys learning without any stress in learning. The knowledge is stimulated with the renovation in the educational sector. In this paper, Multi-Layer Perceptron (MLP) with Back propagation algorithm is used for learners' academic performance prediction that enhance the outcome of the learner. The main contributions of this paper is the effective exploitation of MLP for precise learner performance prediction with OAA learning environment renovating the existing traditional classroom.

This paper is organized as follows: Introduction of Emotional Intelligence is given in section 1 . Section 2 discuss about the review of various authors paper. Section 3 deals with the proposed method. The implementation details is given in section 4 followed by analysis of result in section 5 . The conclusion and future work is given in section 6 .

\section{Literature survey}

In [17] the author studied concluded that various elements of emotional intelligence used as predictors of academic success. In academic contexts, individual self-perceived emotional intelligence (EI) has been shown to be related to better psychological and social adjustment and social adaptation [18] and to school performance in adolescence. A study conducted by [19] predicted that Emotional Intelligence (EI) was related to academic performance where individuals with high Emotional Intelligence would perform better academically. [20] suggests the need to integrate Emotional Intelligence guidance into secondary education curriculum, due to an important connection between Emotional Intelligence and academic achievement. [21] used the statistical technique co-efficient of correlation to analyze the data. The study concluded that there is a positive correlation between Emotional Intelligence and academic achievement of senior secondary students studying in Government schools of Jaipur district. [22] study explored the relationship between Emotional Intelligence and academic performance. Results show that the relationship was quite weak and the level of Emotional Intelligence should be enhanced with advanced in academic progression.

In today's competitive world, producing the brightest experts only is not sufficient. The universities should also spotlight on increasing the complete individuality of the student which consist of intellectual, emotional and social skills that help graduates in their future endeavors [23]. Emotional Intelligence has got more implication for a person in attaining their goals than common intelligence [24]. Evidence about the influence of those variables on subjective well-being, mental health and engagement has been demonstrated along different contexts [25]. The emotional connections students promote in their classrooms are expected to impact their success in school. The study made by [26] examined the association between classroom 
emotional environment and academic achievement, as well as the role of student rendezvous as a mediator. The discussion emphasizes the responsibility of classroom-based, emotion-related interactions to promote academic achievement. Previous research work shows that there exists weak relationship between Emotional Intelligence and academic performance. There is a necessity to connect these two with the academic curriculum.

\section{Proposed work}

With the proposed work given in figure 1 , the learners were made to learn in three different learning environments such as personification, coalition and instructional learning environment where the learners are allowed to learn as a team, share their ideas and thoughts, discuss with illusions, case studies and examples, to raise questions and get answers, to use presentation, to provide feedback and get instructions, alerts and meaningful resource for faculty. The proposed work utilizes Observe, Amend and Analysis (OAA) Method in the Learning Environment (LE). OAA method helps the learner's to balance their emotions while learning. Observation necessitates getting a complete understanding of how a learner think, feel and behave and how a learner impact others. It is very essential to develop thinking of each learner's as it regulates their own behaviour. The emotional feelings such as anger, appreciation, happiness, surprise, anxiety, depression and imaginative are observed during learning in the classroom. The positive and negative interactions of each learner with others in the learning environment are determined by the observation. The outcome of the observations made in the classroom is evaluated and adjustments are made in the learning environment. The analysis is made using data mining algorithms.

\subsection{How to elevate education using emotional intelligence?}

Emotions are natural one to human being. The emotions of human play a major role in the educational sector. Each and every learner come out with different emotions inside the learning environment. The emotions can be varied according to the situation faced by the learner inside and outside the learning environment. The emotions may be either positive, negative or neutral. The most difficult emotion is classified as negative emotion that focuses on awareness. But too many negative emotions can make undergo beset, worried, tired, or strained out. When negative emotions are out of balance, problems may appear too huge to handle. The positive emotions enhance future growth and success. Positive emotions change brains in ways that enhance awareness, attention, and memory which assist to take in additional information, grasp numerous thoughts in mind at once and understand how different thoughts are related to each other. The confidence in oneself helps to increase the positive emotions. The thoughts and actions are expanded using positive emotions that contribute to future success. It is very essential to balance both positive and negative emotions. Thus the outcome of a learner can be improved with the Emotional-Based learning in the learning environment.

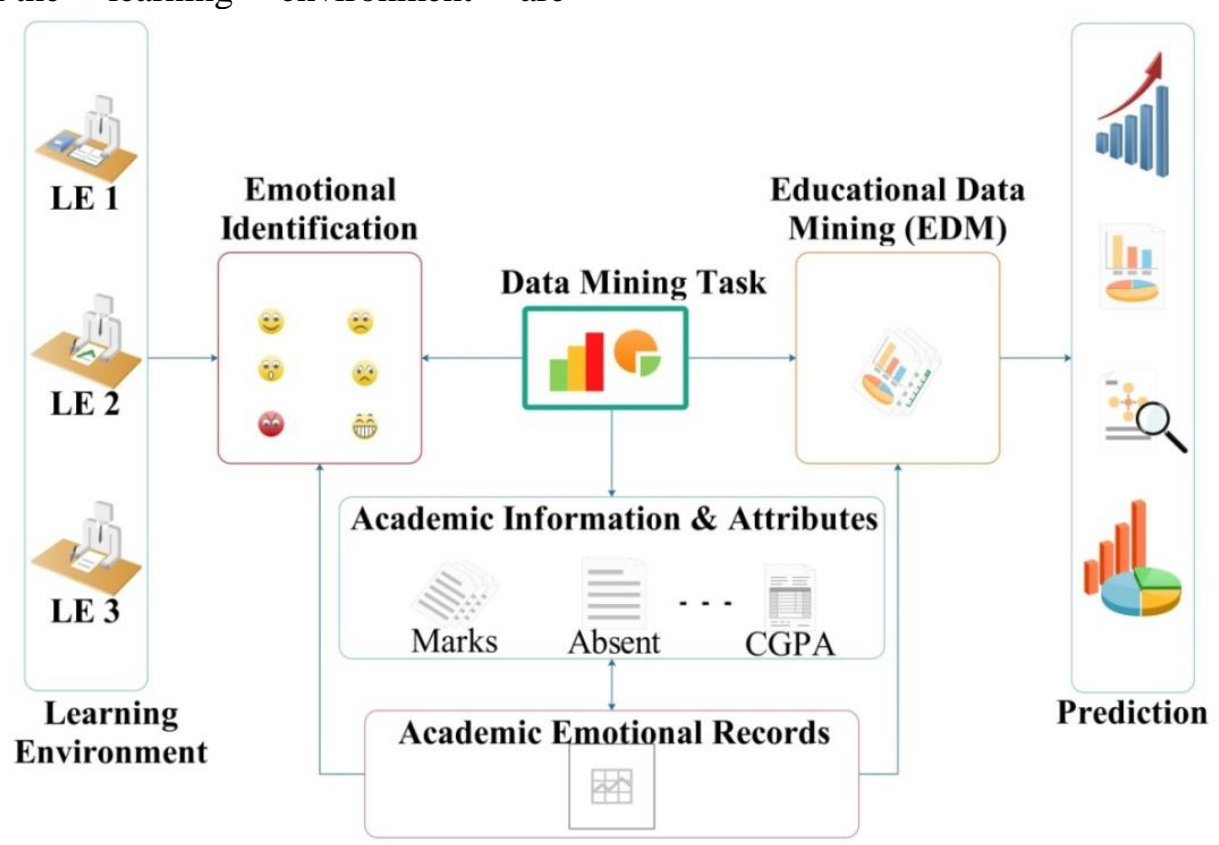

Figure.1 Proposed model of emotional-based learners data mining prediction 


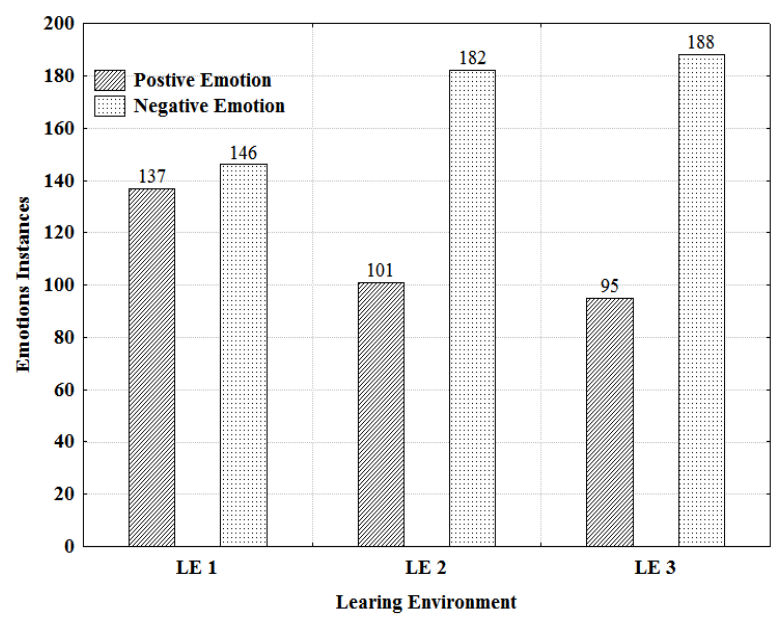

Figure.2 Emotional type in different learning environment

\section{Implementation}

\subsection{Data formation}

The real-time data were collected from an Engineering College. The number of samples taken to develop a proposed model is 283 instances with 12 attributes. The Emotion instance, type approach combines of learning methods in an integrated with three different Learning Environments like (LE1, LE2, LE3) given in Fig. 2.

\subsection{Data transformation}

The dataset is formed with Eight positive emotions and Eleven negative emotions. The data transformation is performed on the dataset, i.e. discrete data are transformed to continuous data. For example these positive emotions are assigned with a continuous value One (1) and the negative emotions with value Zero (0) given in Table1.

\subsection{Multilayer perceptron}

Multilayer Perceptron (MLP) is a network that consists of many neurons, divided in layers, i.e., input layer, hidden layer and output layer where data flows in one direction from input to output layer (feed forward) given in Fig. 3. For each layer, the firing value of each neuron is calculated by getting the sum of the products of the multiplications of all the neurons connected to said neuron from the previous layer and their corresponding weights.

Multilayer Perceptron uses the Back Propagation Algorithm to adjust the weights and biases of the network in order to minimize the mean square error. The weights of a hidden neuron are adjusted in direct proportion to the error, in the neuron to which it is connected. The mean-square error is given by

$$
\begin{aligned}
& J_{M S E}=\frac{1}{2} E\left\{\|d-y\|^{2}\right\} \\
& J_{M S E}=\frac{1}{2} E\left\{\left\|d-x_{\text {out }}^{(3)}\right\|^{2}\right\}
\end{aligned}
$$

Here $\mathrm{d}$ is the desired response and $\mathrm{y}=x_{\text {out }}^{(3)}$ is the corresponding output of the MLP network. The mean square error is the performance index.

Table 1. Data Transformation

\begin{tabular}{|c|c|c|c|}
\hline $\begin{array}{c}\text { Learning } \\
\text { Environme } \\
\text { nt Emotions }\end{array}$ & $\begin{array}{c}\text { Learning } \\
\text { Environment } \\
\text { Emotion ID }\end{array}$ & $\begin{array}{c}\text { Type of } \\
\text { Emotion }\end{array}$ & $\begin{array}{c}\text { Continuous } \\
\text { Value of } \\
\text { Emotion } \\
\text { Type }\end{array}$ \\
\hline Anger & 11 & Negative & 0 \\
\hline Antagonistic & 13 & Negative & 0 \\
\hline Anxiety & 9 & Negative & 0 \\
\hline Bored & 14 & Negative & 0 \\
\hline Dependent & 15 & Negative & 0 \\
\hline Depression & 10 & Negative & 0 \\
\hline Detached & 18 & Negative & 0 \\
\hline Discouraged & 16 & Negative & 0 \\
\hline Frightened & 19 & Negative & 0 \\
\hline Gratitude & 5 & Positive & 1 \\
\hline Happy & 2 & Positive & 1 \\
\hline Hope & 3 & Positive & 1 \\
\hline Imaginative & 4 & Positive & 1 \\
\hline Inspiration & 1 & Positive & 1 \\
\hline Interest & 6 & Positive & 1 \\
\hline Irresponsible & 12 & Negative & 0 \\
\hline Irritated & 17 & Negative & 0 \\
\hline Pleasure & 8 & Positive & 1 \\
\hline Self-control & 7 & Positive & 1 \\
\hline
\end{tabular}

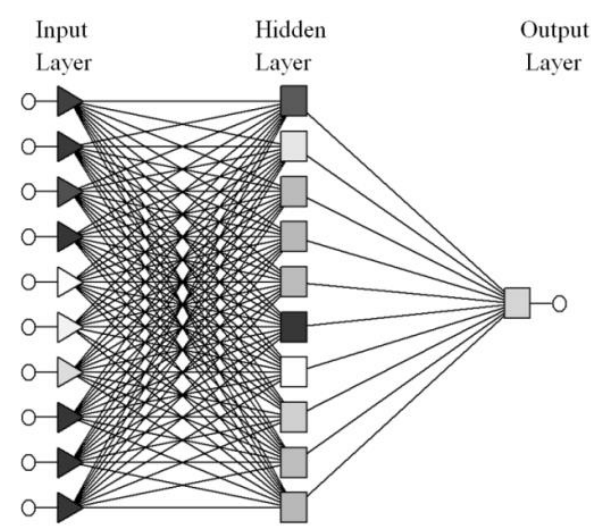

Figure. 3 Architecture of multi-layer perception 


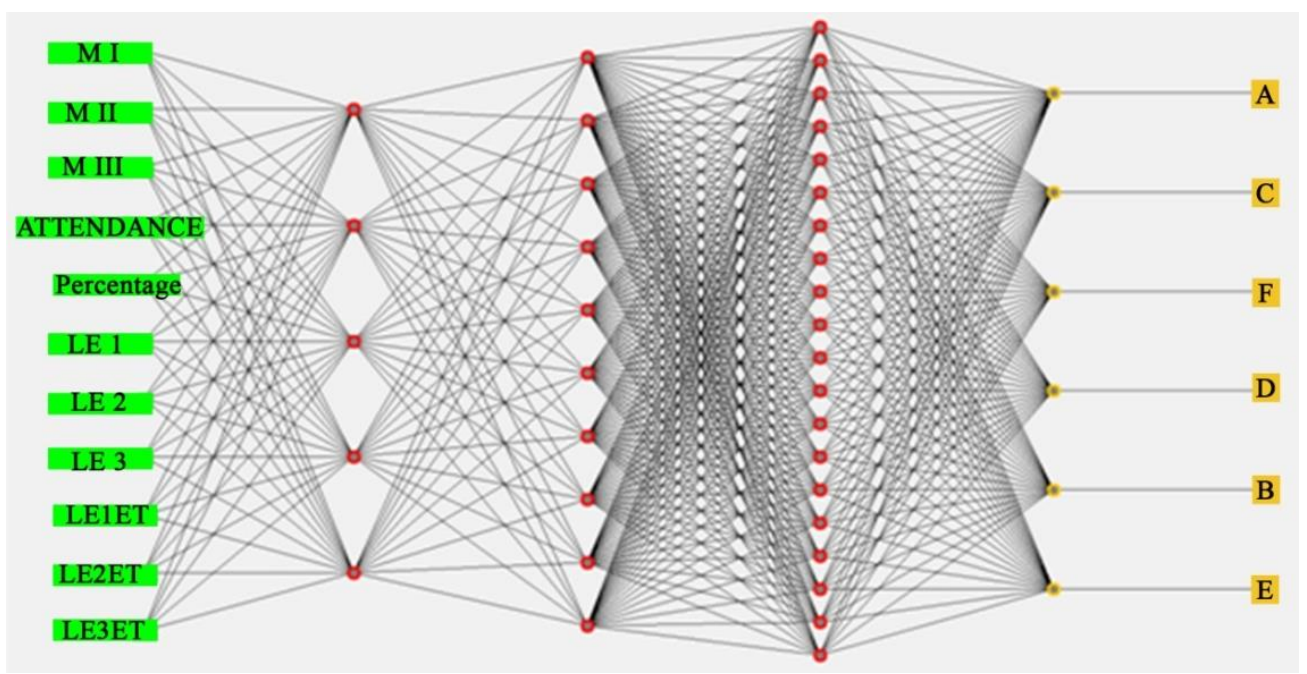

Figure.4 Training of network with 3 hidden layers

\subsection{Back propagation algorithm}

1. Create a network with input, hidden and output layer.

2. Initialize weights to small random number

3. for each sample in training set do

\subsection{Forward Pass}

$$
\begin{aligned}
& y_{h}=\sigma\left(\sum_{i} w_{h i} x_{i}\right) \\
& \delta_{h}=y_{h}\left(1-y_{h}\right) \sum_{k} w_{h k} \delta_{k}
\end{aligned}
$$

\subsection{Backward Pass}

$$
\begin{aligned}
& y_{k}=\sigma\left(\sum_{k} w_{k h} x_{h}\right) \\
& \delta_{k}=y_{k}\left(1-y_{k}\right)\left(t_{k}-y_{k}\right)
\end{aligned}
$$

\subsection{Update each network weights $W_{i j}$}

$$
w_{i j} \leftarrow w_{i j}+\Delta w_{i j}
$$

with

$$
\Delta w_{i j}=\eta \delta_{j} x_{i j}
$$

$$
\text { end }
$$

\section{Do until stopping criteria is reached}

\section{\# Initialize network with random weights}

For each training samples

do

Provide training inputs to network and calculate output

For each layer

$$
\text { do }
$$

Compare network output with correct output Adapt weights in current layer end

\section{Result analysis}

The learners dataset is implemented with MLP Back Propagation Algorithm. The training of network with 11 input layers, $3(5,10,20)$ hidden layers and 6 output layers are given in Fig. 4. The parameters such as learning rate, momentum for Multilayer Perceptron was set before network training.

The proposed work uses the following IF-THEN rule to assign grades:

$$
\begin{aligned}
& \text { If Marks } \geq 90 \text { Then CGPA }={ }^{\prime} A \\
& \text { If Marks } \geq 80 \text { Then CGPA }={ }^{\prime} B^{\prime} \\
& \text { If Marks } \geq 70 \text { Then CGPA }={ }^{\prime} C^{\prime} \\
& \text { If Marks } \geq 60 \text { Then CGPA }={ }^{\prime} D^{\prime} \\
& \text { If Marks } \geq 50 \text { Then CGPA }={ }^{\prime} E^{\prime} \\
& \text { If Marks }<50 \text { Then CGPA }=' F^{\prime}
\end{aligned}
$$

The metrics used to measure the performance are Confusion Matrix, Accuracy, Precision and Recall, F measure, Area Under the ROC (Receiver Operating Characteristic) Curve. The confusion matrix of the implementation is given in Table 2. In the confusion matrix, the diagonals represent instances classified correctly according to reference data and the off-diagonals were misclassified.

Accuracy is essential to grasp of the kappa statistic and is exemplified through the use of confusion matrix. The accuracy is defined as the number of correct plots to the total number of plots.

$$
\text { Accuracy }=\frac{\text { Number of correct plots }}{\text { total number of plots }}
$$


Table 2. Confusion matrix

\begin{tabular}{|c|c|c|c|c|c|c|c|c|}
\hline \multirow{8}{*}{ 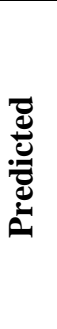 } & \multicolumn{7}{|c|}{ Truth } & \multirow{2}{*}{ Predicted Output } \\
\hline & CGPA & $\mathbf{A}$ & B & C & D & $\mathbf{E}$ & $\mathbf{F}$ & \\
\hline & $\mathbf{A}$ & 25 & 0 & 0 & 0 & 0 & 0 & $\mathbf{A}$ \\
\hline & B & 0 & 21 & 0 & 3 & 1 & 0 & $\mathrm{C}$ \\
\hline & C & 0 & 0 & 88 & 0 & 0 & 0 & $\mathbf{F}$ \\
\hline & D & 0 & 3 & 0 & 50 & 0 & 1 & D \\
\hline & $\mathbf{E}$ & 4 & 3 & 0 & 0 & 14 & 0 & B \\
\hline & $\mathbf{F}$ & 0 & 0 & 0 & 0 & 0 & 70 & $\mathbf{E}$ \\
\hline
\end{tabular}

The overall classification accuracy of the implemented algorithm with 283 instances is $94.6996 \%$ i.e. about $95 \%$ are correctly classified, and $5 \%$ are classified with errors. This is quite a high accuracy. The producer and user accuracy is given in Table 2. Producer accuracy is the probability that a value in a given class was classified correctly. User accuracy is the probability that a value predicted to be in a certain class really is that class. The producer's accuracy of the $\mathrm{C}$ class was $100 \%$ and the user's accuracy was $100 \%$. This implies that $100 \%$ of the reference C Grade have been correctly identified as "C", as well as $100 \%$ percent of the Grade identified as "C" in the classification were actually $\mathrm{C}$. The producer's accuracy for the A class was $100 \%$, while the user's accuracy was $86.2 \%$. This means that even though $100 \%$ of the reference A Grade have been correctly identified as "A", only $86.2 \%$ percent of the Grade identified as " $A$ " in the classification were actually A. F-measure is a measure that combines precision and recall is the harmonic mean of precision and recall, where an F-measure score reaches its best value at 1 and worst at 0 .

$$
F-\text { measure }=2 \times \frac{(\text { Precision } \times \text { Recall })}{(\text { Precision }+ \text { Recall })}
$$

From the Table 3, for grade $\mathrm{C}$, the F-measure score is 1 which is the best value compared to other grade implies that this work was built with more number of CGPA with ' $C$ ' than other CGPA and the test data contains mostly CGPA with 'C'.

Commission error represents pixels that belong to another class, but are labeled as belonging to the class. The commission error is given by

$$
\text { Commission Error }=\frac{\text { off Diagonal row elements }}{\text { Total of Row }}
$$

The amount of errors of commission is described by the Producer's accuracy indicator given in Table 3. Errors of commission, which is a measure of false positives are shown in the rows of the confusion matrix, except for the values along the diagonal.
Table 3. Precision, Recall and F-measure

\begin{tabular}{|c|c|c|c|}
\hline CGPA & Precision & Recall & F-Measure \\
\hline A & 0.862 & 1 & 0.926 \\
\hline B & 0.778 & 0.84 & 0.808 \\
\hline C & 1 & 1 & 1 \\
\hline D & 0.943 & 0.926 & 0.935 \\
\hline E & 0.933 & 0.667 & 0.778 \\
\hline F & 0.986 & 1 & 0.993 \\
\hline
\end{tabular}

Table 4. Classification of errors

\begin{tabular}{|l|c|c|}
\hline Grade & $\begin{array}{c}\text { Errors of } \\
\text { commission }\end{array}$ & $\begin{array}{c}\text { Errors of } \\
\text { omission }\end{array}$ \\
\hline A & 0 & 13.79310345 \\
\hline B & 16 & 22.22222 \\
\hline C & 0 & 0 \\
\hline D & 7.407407 & 5.660377 \\
\hline E & 33.33333 & 6.666667 \\
\hline F & 0 & 1.408451 \\
\hline
\end{tabular}

Omission error represents pixels that belong to the truth class but fail to be classified into the proper class. The omission error is given by

Omission Error $=\frac{\text { off Diagonal column elements }}{\text { Total of Column }}$

The amount of errors of omission is described by the User's accuracy given in Table 4. Errors of omission which is a measure of false negatives are shown in the columns of the confusion matrix, except for the values along the main diagonal. The percentage of classification of errors are given in Fig. 5.

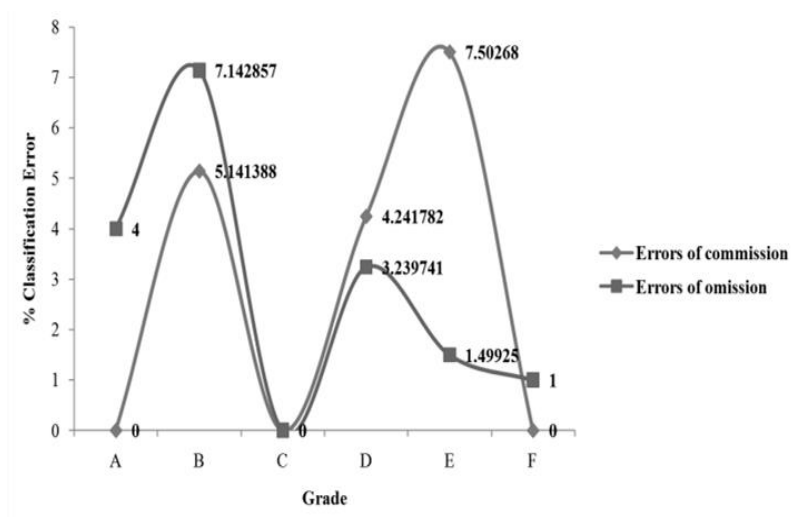

Figure.5 Percentage classification of errors 
Mean Absolute Error (MAE) is the average over the test sample of the absolute differences between prediction and actual observation where all individual differences have equal weight.

$$
M A E=\frac{1}{n} \sum_{j=1}^{n}\left|\hat{\theta}_{j}-\theta_{j}\right|
$$

where $\theta_{j}$ is the prediction and $\hat{\theta}_{j}$ the true value.

Mean Absolute Error is 0.0258

Root Mean Squared Error (RMSE) is the square root of the average of the squared differences between prediction and actual observation.

$$
R M S E=\sqrt{\frac{1}{n} \sum_{j=1}^{n}\left(\hat{\theta}_{j}-\theta_{j}\right)^{2}}
$$

where $\theta_{j}$ is the prediction and $\hat{\theta}_{j}$ the true value.

The accuracy of the students' performance prediction is measured by finding the variation between performance of the actual observed data values and the ones predicted by the model.

Root Mean Squared Error is 0.12.

The Relative Absolute Error (RAE) can be compared between models whose errors are measured in the different units. The relative absolute error takes the total, absolute error and normalizes it by dividing by the total absolute error of the simple predictor.

$$
R A E=\frac{\sum_{j=1}^{n}\left|\widehat{\theta}_{j}-\theta_{j}\right|}{\sum_{j=1}^{n}\left|\bar{\theta}-\theta_{j}\right|}
$$

where $\bar{\theta}$ is a mean value of $\theta$.

where $\theta_{j}$ is the prediction and $\hat{\theta}_{j}$ the true value.

Relative Absolute Error is $9.8619 \%$

The Root Relative Squared Error (RRSE) is the average of the actual values. Thus, the relative squared error takes the total squared error and normalizes it by dividing by the total squared error of the simple predictor. By taking the square root of the relative squared error one reduces the error to the same dimensions as the quantity being predicted.

$$
R R S E=\sqrt{\frac{\sum_{j=1}^{n}\left(\widehat{\theta}_{j}-\theta_{j}\right)^{2}}{\sum_{j=1}^{n}\left(\bar{\theta}-\theta_{j}\right)^{2}}}
$$

where $\theta_{j}$ is the prediction and $\hat{\theta}_{j}$ the true value.

Root Relative Squared Error is $33.1876 \%$

The model achieved the best learners' performance prediction with RMSE of 0.12 in 500 Epochs compared to the prediction of model ANFIS-GbellMF with RMSE of 0.193 in 1000 epochs discussed in [27] and the RMSE value of 2.3 attained by LION-WOLF Neural Network in [28].

Kappa index of agreement gives an overall assessment of the accuracy of the classification. The Kappa statistic is a metric that compares an $\mathrm{P}_{0}$ observed accuracy (the number of instances that were classified correctly throughout the entire confusion matrix) with an $\mathrm{P}_{\mathrm{e}}$ expected accuracy (is directly related to the number of instances of each class along with the number of instances that the machine learning classifier). The kappa statistic is used to evaluate classifiers amongst themselves. The Kappa statistic is given by

$$
\widehat{K}=\frac{P_{0}-P_{e}}{1-P_{e}}
$$

The Kappa statistic $(\widehat{K})$ varies from 0 to 1 , where.

- $0=$ agreement equivalent to chance.

- $0.1-0.20=$ slight agreement.

- $0.21-0.40=$ fair agreement.

- $0.41-0.60=$ moderate agreement.

- $0.61-0.80=$ substantial agreement.

- $0.81-0.99=$ near perfect agreement

- $1=$ perfect agreement.

Using the above formula, $\widehat{\boldsymbol{K}}$ is $\mathbf{0 . 9 3 2 4}$ which is almost perfect agreement [29] with good accuracy of learner performance prediction (table. 6). The detailed accuracy by class is given in table 5. Kappa is always less than or equal to 1 . A value of 1 implies perfect agreement and values less than 1 imply less than perfect agreement.

The Area under ROC Curve is used for measuring performance of binary classifiers that has the ability to correctly differentiate instances of different classes. In the case of classification, as the Area under ROC Curve value is greater than 0.9 the classifier is excellent given in Fig. 6. The time taken to build this model is 16.49 seconds.

Table 5. Detailed Accuracy by Class [30]

\begin{tabular}{|c|c|c|c|c|c|}
\hline $\begin{array}{c}\text { Values } \\
\text { prediction }\end{array}$ & $\begin{array}{c}\text { TP } \\
\text { Rate }\end{array}$ & $\begin{array}{c}\text { FP } \\
\text { Rate }\end{array}$ & $\begin{array}{c}\text { F- } \\
\text { Measure }\end{array}$ & $\begin{array}{c}\text { ROC } \\
\text { Area }\end{array}$ & Class \\
\hline \multirow{4}{*}{} & 1 & 0.016 & 0.926 & 0.999 & A \\
\cline { 2 - 6 } & 0.84 & 0.023 & 0.808 & 0.984 & C \\
\cline { 2 - 6 } & 1 & 0 & 1 & 1 & F \\
\cline { 2 - 6 } & 0.926 & 0.013 & 0.935 & 0.994 & D \\
\cline { 2 - 6 } & 0.667 & 0.004 & 0.778 & 0.985 & B \\
\cline { 2 - 6 } & 1 & 0.005 & 0.993 & 1 & E \\
\hline $\begin{array}{l}\text { Weighted } \\
\text { Average }\end{array}$ & $\mathbf{0 . 9 4 7}$ & $\mathbf{0 . 0 0 7}$ & $\mathbf{0 . 9 4 6}$ & $\mathbf{0 . 9 9 6}$ & \\
\hline
\end{tabular}


The results of the implementation depict that learning with positive emotion produces a good outcome compared to the negative emotions.

The data mining algorithms such as Bagging, AdaBoost, J48, Logistic, random Forest, Stacking, Vote, BESTrees and IBk are implemented with the emotional-based learners dataset is given in Table 7 . The decision tree bagging ensemble achieved higher accuracy.

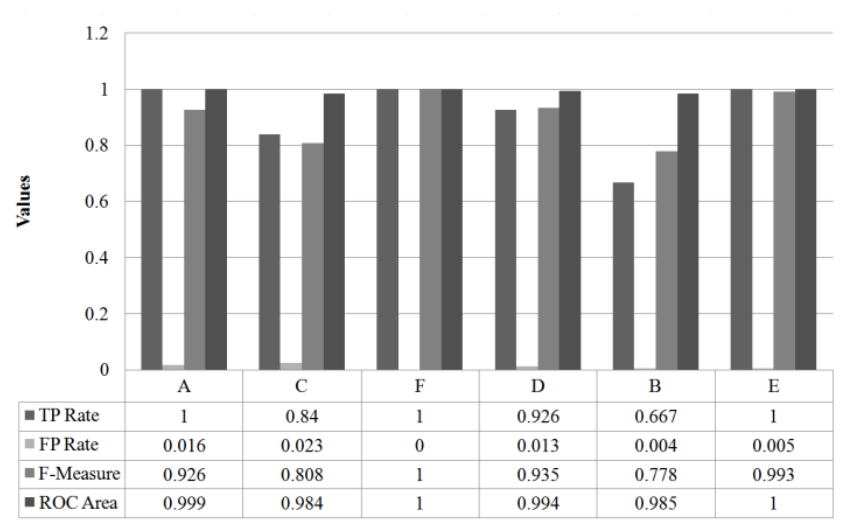

Figure.6 Accuracy by Class [30]
Table 6. Detailed Kappa statistic

\begin{tabular}{|c|c|}
\hline Algorithm & Kappa statistic \\
\hline Bagging & 0.991 \\
\hline AdaBoost & 0.3286 \\
\hline J48 & 0.9865 \\
\hline IBk & 0.6123 \\
\hline Logistic & 0.8468 \\
\hline Random Forest & 0.982 \\
\hline Stacking & 0.9685 \\
\hline Vote & 0.9865 \\
\hline BESTrees & 0.991 \\
\hline MLP & 0.9324 \\
\hline
\end{tabular}

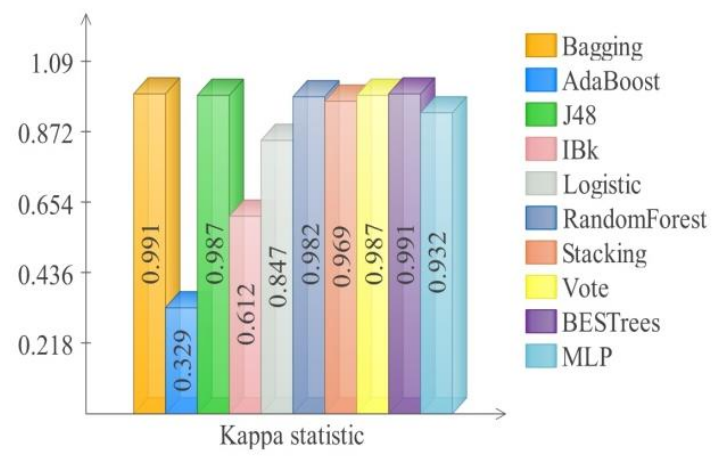

Figure 8. Kappa Statistic

Table 7. Comparative analysis of emotional based learners with various data mining algorithms

\begin{tabular}{|c|c|c|c|c|c|c|c|c|}
\hline \multicolumn{9}{|c|}{ Stratified Cross-Validation } \\
\hline Algorithm & $\begin{array}{c}\text { Correctly } \\
\text { Classified } \\
\text { Instances }\end{array}$ & $\begin{array}{c}\text { Incorrectly } \\
\text { Classified } \\
\text { Instances }\end{array}$ & $\begin{array}{c}\text { Kappa } \\
\text { statistic }\end{array}$ & $\begin{array}{c}\text { Mean } \\
\text { absolute } \\
\text { error }\end{array}$ & $\begin{array}{c}\text { Root mean } \\
\text { squared } \\
\text { error }\end{array}$ & $\begin{array}{c}\text { Relative } \\
\text { absolute } \\
\text { error }\end{array}$ & $\begin{array}{c}\text { Root relative } \\
\text { squared } \\
\text { error }\end{array}$ & $\begin{array}{c}\text { Total } \\
\text { Number of } \\
\text { Instances }\end{array}$ \\
\hline Bagging & $99.29 \%$ & $0.71 \%$ & 0.991 & 0.0079 & 0.0558 & $3.03 \%$ & $15.43 \%$ & 283 \\
\hline AdaBoost & $50.18 \%$ & $49.82 \%$ & 0.3286 & 0.1957 & 0.3129 & $74.73 \%$ & $86.52 \%$ & 283 \\
\hline J48 & $98.94 \%$ & $1.06 \%$ & 0.9865 & 0.0035 & 0.0594 & $1.35 \%$ & $16.44 \%$ & 283 \\
\hline IBk & $69.61 \%$ & $30.39 \%$ & 0.6123 & 0.1054 & 0.3147 & $40.22 \%$ & $87.01 \%$ & 283 \\
\hline Logistic & $87.99 \%$ & $12.01 \%$ & 0.8468 & 0.0376 & 0.1883 & $14.36 \%$ & $52.08 \%$ & 283 \\
\hline RandomForest & $98.59 \%$ & $1.41 \%$ & 0.982 & 0.0306 & 0.0832 & $11.67 \%$ & $23.00 \%$ & 283 \\
\hline Stacking & $97.53 \%$ & $2.47 \%$ & 0.9685 & 0.0098 & 0.0939 & $3.74 \%$ & $25.96 \%$ & 283 \\
\hline Vote & $98.94 \%$ & $1.06 \%$ & 0.9865 & 0.0544 & 0.1611 & $20.78 \%$ & $44.54 \%$ & 283 \\
\hline BESTrees & $99.29 \%$ & $0.71 \%$ & 0.991 & 0.0097 & 0.0445 & $3.69 \%$ & $12.30 \%$ & 283 \\
\hline
\end{tabular}

Table 8. Metrics analysis of various algorithms

\begin{tabular}{|c|l|c|c|c|c|c|c|}
\hline Accuracy & Algorithm & TP Rate & FP Rate & Precision & Recall & F-Measure & ROC Area \\
\hline \multirow{4}{*}{} & Bagging & 0.993 & 0.001 & 0.993 & 0.993 & 0.993 & 0.997 \\
\cline { 2 - 8 } & AdaBoost & 0.502 & 0.171 & 0.256 & 0.502 & 0.338 & 0.806 \\
\cline { 2 - 8 } & J48 & 0.989 & 0.002 & 0.99 & 0.989 & 0.989 & 0.994 \\
\cline { 2 - 8 } & IBk & 0.696 & 0.071 & 0.698 & 0.696 & 0.695 & 0.809 \\
\cline { 2 - 8 } & Logistic & 0.88 & 0.028 & 0.88 & 0.88 & 0.88 & 0.988 \\
\cline { 2 - 8 } & Random Forest & 0.986 & 0.003 & 0.986 & 0.986 & 0.986 & 1 \\
\cline { 2 - 8 } & Stacking & 0.975 & 0.006 & 0.975 & 0.975 & 0.975 & 0.996 \\
\cline { 2 - 8 } & Vote & 0.989 & 0.002 & 0.99 & 0.989 & 0.989 & 0.997 \\
\cline { 2 - 8 } & BESTrees & 0.993 & 0.002 & 0.993 & 0.993 & 0.993 & 0.991 \\
\hline \multirow{2}{*}{} & & & & & &
\end{tabular}



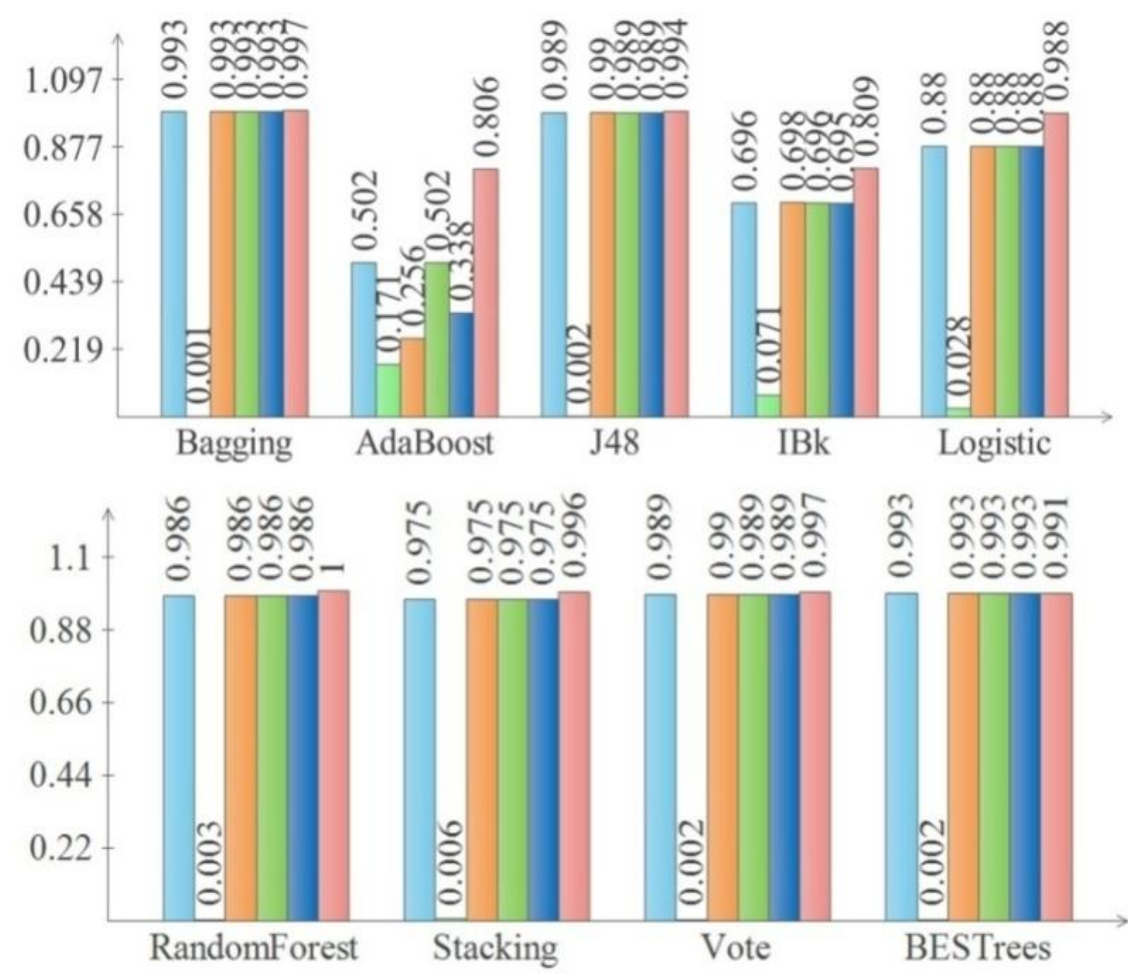

$\square$ TP Rate $\square$ FP Rate $\square$ Precision $\square$ Recall $\square$ F-Measure $\square$ ROC Area

Figure.9 Analysis of various algorithms

The metrics are evaluated for various data mining algorithms are specified in Table 8 and the chart of accuracy is given in Fig. 9. The ROC area and $\mathrm{F}$ measure is highest in the present work when compared to the work in [30] that implies the proposed work predict learner performance in the academics well.

\section{Conclusion}

The present work aims at improving the placement opportunities by proposing models based on theoretical design. We have developed a classification to classify learners data. The methodology has developed using a real time database, on which the classification algorithms is applied for classifying learner's data. The results derived from this are used in for identifying the gap related to learning, employability and the recommended training to be given. The proposed work utilizes the emotion-based learning with an OAA method to increase the learners learning in the learning environment. The method implemented deals with the emotional feelings of a learner and aid the learner to adhere to the learning environment with positive emotions. The thinking, creativity and learning capability of a learner is enhanced with a proposed which overcomes the traditional method of teaching. In this work, it is showed that emotional- based learner data can show a huge improvement in predictive accuracy. The comparison is made with various techniques and show that using ensemble models not only gives better predictive accuracies on learner performance, but also provides better rules for understanding the factors that influence better learner outcomes. The system can be further enhanced by introducing other aspects related to the educational system and a completed academic review system can be developed. In our future work, to explore other data mining algorithms to identify groups of learner who have similar academic performance.

\section{References}

[1] S.L. Beilock and G. Ramirez, "On the interplay of emotion and cognitive control: Implications for enhancing academic achievement", In J.P. Mestre, B.H. Ross, Psychology of learning and motivation: Cognition in education, Vol. 55, pp. 137-169, 2011.

[2] R. Pekrun and P.A. Schutz, "Where do we go from here? Implications and future directions for inquiry on emotions in education", In P.A. Schutz, and R. Pekrun, Emotion in education. Amsterdam, The Netherlands: Elsevier, pp. 313331, 2007. 
[3] M. Csikszentmihalyi and I.S. Csikszentmihalyi, "Optimal experience: Psychological studies of flow in consciousness", Cambridge, UK: Cambridge University Press, 1988.

[4] R. Pekrun, A.C. Frenzel, T. Goetz, and R.P. Perry, "The control value theory of achievement emotions: An integrative approach to emotions in education", In P.A. Schutz, R. Pekrun, Emotion in education. Amsterdam, The Netherlands: Elsevier, pp. 13-36, 2007.

[5] M. Boekaerts, "Context sensitivity: Activated motivational beliefs, current concerns and emotional arousal", In S. Volet, S. Jarvela, Motivation in learning contexts: Theoretical advances and methodological implications, Elmsford, NY: Pergamon Press, pp. 17-31, 2001.

[6] K.F. Osterman, "Teacher practice and students' sense of belonging", In T. Lovat, R. Toomey, and $\mathrm{N}$. Clement, International Research Handbook on Values Education and Student Wellbeing Dordrecht, The Netherlands: Springer, pp. 239-260, 2010.

[7] W. Wang, H. Yin, and S. Huang, "The missing links between emotional job demand and exhaustion and satisfaction: Testing a moderated mediation model", Journal of Management \& Organization, Vol. 22, pp.80-95, 2016.

[8] M.H. Ashcraft and E.P. Kirk, "The relationships among working memory math anxiety and performance", Journal of Experimental Psychology General, Vol. 130, No. 1, pp. 224237, 2001.

[9] S. Darke, "Effects of anxiety on inferential reasoning task performance", Journal or Personality and Social Psychology, Vol. 55, No. 3, pp. 499-505, 1988.

[10] B.A. Sorg and P. Whitney, "The effect of trait anxiety and situational stress on working memory capacity", Journal of Research Personality, Vol. 26, pp. 235-241, 1992.

[11] M. Oaksford, F. Morris, B. Grainger, and J.M.G. Williams, "Mood, reasoning, and central executive processes", Journal of Experimental Psychology Learn, Memory, and Cognitive, Vol. 22, No. 2, pp.476-92, 1996.

[12] P.S. Seibert and H.C. Ellis, "Irrelevant thoughts, emotional mood states, and cognitive task performance", Memory Cognitive, Vol. 19, No. 5, pp. 507-513, 1991.

[13] A. Yahaya, N.S. Ee, J.D.J. Bachok, Yahaya, N, Y. Boon, N. Hashim, and M.G. Lee, "The impact of emotional intelligence element on academic achievement", Archives Des Sciences, Vol. 65, No. 4, pp. 2-16, 2012.
[14] M.A.M. Mohzan, N. Hassan, and N.A. Hallil, "The influence of emotional intelligent on academic achievement", Procedia - Social and Behavioural Sciences, Vol. 90, No. 10, pp. 303312, 2013.

[15] Y. Zhu, C. Liu, M. Guo, L. Zhao, and F.L Lou, "The impact of emotional intelligence on work engagement of registered nurses: The mediating role of organisational justice", Journal of Clinical Nursing, Vol. 24, pp.2115-2124, 2015.

[16] S. Chamundeswari, "Emotional intelligence and academic achievement among students at higher secondary level", International Journal of Academic Research in Economics and Management Sciences, Vol. 2, No. 4, pp.178187, 2013.

[17] J.D.A. Parker, L.J. Summerfeldt, M.J. Hogan, and S. Majeski, "Emotional Intelligence and academic success: Examining the transition from high school to university", Personality and Individual Differences, Vol. 36, pp. 163172, 2004.

[18] I. Pedrosa, J. Suarez-Alvarez, M. Lozano, J. Muniz, and E. Garcia-Cueto, "Assessing perceived emotional intelligence inadolescents: New validity evidence of Trait Meta-Mood Scale-24", Journal of Psychoeducational Assessment, Vol. 32, No. 8, pp. 737-746, 2014.

[19] J. Rode, C. Mooney, M. Arthaudday, J. Near, T. Baldwin, R. Rubin, and W. Bommer, "Emotional intelligence and individual performance: Evidence of direct and moderated effects", Journal of Organizational Behavior, Vol. 28, pp. 399-421, 2007.

[20] H. Svetlana, "Emotional Intelligence And Academic Achievement In Higher Education", Pepperdine University, 2007.

[21] M. Poonam, "A Study of the Effect of Emotional Intelligence on Academic Achievement of Jaipur Senior Secondary Students", International Journal of Educational Research and Technology, Vol. 3, No. 4, pp. 25 $-28,2012$.

[22] Z.M. Sania and S. Sehrish, "Effect of Emotional Intelligence on Academic Performance among Business Students in Pakistan”, Bulletin of Education and Research, Vol. 38, No. 1, pp. 197-208, 2016.

[23] C.R. Seal, S.E. Naumann, A. Scott, and J. Roycedavis, "Social emotional development: A new model of learning in higher education", Research in Higher Education Journal, Vol. 10, No. 1, pp. 1-13, 2011.

[24] V. Joshi, K. Srivastava and A. Raychaudhuri, "A descriptive study of emotional intelligence 
and academic performance of MBBS students", Social and Behavioral Sciences, Vol. 69, No. 1, pp. 2061-2067, 2012.

[25] A. F. Rodriguez, E. D. Ramos, A.Z. Fernandez, E. Goni, I. Esnaola, and A. Goni, "Contextual and psychological variables in a descriptive model of subjective well-being and school engagement", International Journal of Clinical and Health Psychology, Vol.16, pp.166-174, 2016.

[26] R.R. Maria, A.B. Marc, E.R Susan, W. Mark, and S. Peter, "Classroom Emotional Climate, Student Engagement, and Academic Achievement", Journal of Educational Psychology, Vol. 104, No. 3, pp. 700-712, 2012.

[27] A. Altyeb and B. Omar, "Prediction of Student's Academic Performance Based on Adaptive Neuro-Fuzzy Inference", International Journal of Computer Science and Network Security, Vol.17, No.1, pp. 165-169, 2017.

[28] L. Ramanathan, G. Angelina, M. Khalid, and P. Swarnalatha, "Student Performance Prediction Model Based on Lion-Wolf Neural Network", International Journal of Intelligent Engineering and Systems, Vol.10, No.1, pp.114-123, 2017.

[29] D. Magdalene, P. Ramasubramanian, and I. Samuel, "Increased Success Outcome Of A Learner With Ensemble Teaching And Analysis With Naive Bayes Algorithm", Ciência $e$ Técnica Vitivinícola Journal, Vol 32, Issue 6, pp. 59-73, 2017.

[30] M. Tripti, K. Dharminder, and G. Sangeeta, "Students Employability Prediction Model through Data Mining", International Journal of Applied Engineering Research, Vol. 11, No. 4, pp 2275-2282, 2016. 